\title{
Syndromes of transient amnesia: towards a classification. A study of 153 cases
}

\author{
J R Hodges, C P Warlow
}

\begin{abstract}
Of 153 patients presenting with acute transient amnesia, 114 fulfilled the proposed strict diagnostic criteria for transient global amnesia (TGA). The prognosis of this group was excellent with the exception of a small subgroup $(7 \%)$, largely identifiable because of atypically brief or recurrent attacks, who developed epilepsy of temporal lobe type on follow up. Computerised tomography (CT) scans performed on 95 patients were normal, evidence for covert alcoholism was lacking and there was a familial incidence of approximately $2 \%$. By contrast, the group of 39 patients who did not meet the criteria for TGA had a significantly worse prognosis with a high incidence of major vascular events. The groups could not be distinguished on the basis of behavioural characteristics during the attack. The following classification was proposed: 1) pure TGA-attacks fulfilling the strict criteria, and of more than one hour in duration which do not require detailed investigation, 2) probable epileptic amnesia-attacks of less than an hour or rapidly recurrent, 3 ) probable transient ischaemic amnesia, a minority of cases with additional focal neurological deficits during the attack.
\end{abstract}

The term TGA was first coined by Fisher and Adams $^{12}$ to describe a clinical syndrome, characterised by the abrupt onset of severe anterograde amnesia, usually accompanied by repetitive questioning, which occurred in the middle aged or elderly. During the attack the patients remained alert and communicative, and personal identity was preserved. Focal neurological and epileptic features were absent, and general cognition appeared intact. After a few hours the ability to lay down new memories gradually recovered and subjects returned to normal except for a dense amnesic gap for the duration of the attack. Interestingly, the same syndrome was undoubtedly described by other authors at about the same time but under different titles. ${ }^{3-5}$

Despite the fact that over a thousand cases of TGA have now been reported its aetiology remains unknown. The most widely held view is that it is due to cerebrovascular disease of the thromboembolic type. ${ }^{6-12}$ Other authors support epilepsy as the cause ${ }^{13-15}$ and more recently strong aetiological claims have been made for migraine. ${ }^{16}{ }^{17}$ In addition, there have been cases that have been reported associating
TGA with a variety of conditions including cerebral angiography, ${ }^{18}{ }^{19}$ cerebral tumours ${ }^{202}$ and cerebral haemorrhage. ${ }^{22}$

Elsewhere we, ${ }^{2324}$ and others, ${ }^{25}$ have argued that much of this aetiological uncertainty results from the lack of generally agreed diagnostic criteria coupled with the lack of sound epidemiological studies. The early authors were highly restrictive in their use of the diagnosis. Subsequently, the term has been applied to a variety of different clinical situations merely sharing the feature of prominent memory loss. ${ }^{25}$ Whilst some authors have included patients with unwitnessed attacks or with focal neurological features during the attack, others excluded such cases. The possibility that "pure TGA" may have a different aetiology to transient amnesia with additional neurological features has not been properly considered.

The diagnostic criteria proposed by Caplan $^{25}$ are now gaining acceptance and were used in two recent large clinical studies. ${ }^{2627}$ However, there have been no attempts to validate these criteria, to assess whether they designate a distinct group of patients with acute amnesia or to see how successfully these relatively stringent criteria can be applied in clinical practice.

Between 1984-87 we conducted a casecontrol study of TGA in which diagnostic criteria derived from Caplan ${ }^{25}$ were applied. In this paper we report the clinical features and outcome of the TGA cases included in the study and contrast these with the cases of acute transient memory loss excluded from the study (the non-TGA cases). The main purpose was to assess the usefulness of the proposed diagnostic criteria and to establish whether subgroups of patients with different prognoses can be identified on the basis of their clinical features at presentation.

In addition, we were able to address certain controversial clinical aspects including the prevalence of CT scan abnormalities ${ }^{11} 122829$ and a family history of TGA. ${ }^{30-32}$ We also draw attention to some previously neglected clinical features, such as the presence of a permanent retrograde gap post-attack, and assess the possible contribution of alcoholism which although known to cause amnesic "blackouts" 33 has not been considered in the aetiology of TGA.

\section{Subjects and methods}

Diagnostic criteria for definite TGA

a) Attacks must be witnessed and information available from a capable observer who was present for most of the attack. 
b) There must be clear-cut anterograde amnesia during the attack.

c) Clouding of consciousness and loss of personal identity must be absent, and the cognitive impairment limited to amnesia (that is, no aphasia, apraxia, etc).

d) There should be no accompanying focal neurological symptoms during the attack and no significant neurological signs afterwards.

e) Epileptic features must be absent.

f) Attacks must resolve within 24 hours.

g) Patients with recent head injury or active epilepsy (that is, remaining on medication or one seizure in the past two years) are excluded.

\section{Patients}

The 153 cases included in the study were ascertained by two means:

1) In 1984 we wrote to all general practitioners in the Oxfordshire Region asking them to refer any potential cases of TGA. The consultant neurologists in the Region and the Oxfordshire Community Stroke Project $(\mathrm{OCSP})^{34}$ also participated in the study. A total of 84 patients were referred for assessment between 1984-87 and were designated the prospective group. All patients were seen by one of the authors ( $\mathrm{JH})$ at an interval after the attack, and 12 were examined during the acute episode. Five of these had detailed neuropsychological testing as described elsewhere. ${ }^{23}$

Of the 84 prospective cases, 63 fulfilled the criteria for definite TGA and 21 (non-TGA cases) were excluded for the reasons shown in table 1.

2) A further 69 cases were ascertained after reviewing all possible cases of TGA seen in the Department of Neurology in Oxford between 1977 and 1984. These were designated the retrospective group. The majority had originally been seen by the authors and comprehensive data were available on all cases comparable to the prospective group. Of the 69 cases, 51 met the criteria for definite TGA and 18 (non-TGA cases) were excluded for the reasons given in table 1 . All patients were interviewed (by $\mathrm{JH}$ ) in 1984 and their general practitioners were also contacted to provide information on amnesic attacks, vascular events and other medical problems since their presentation. From 1984 until 1987 all were kept under regular follow up as described below.

Comparison of the demographic, clinical

Table 1 Constitution of the retrospectively and prospectively collected patient groups and reasons for exclusion from the definite TGA category

\begin{tabular}{lllr}
\hline & $\begin{array}{l}\text { Prospective } \\
\text { Group }\end{array}$ & $\begin{array}{l}\text { Retrospective } \\
\text { Group }\end{array}$ & $\begin{array}{l}\text { Total } \\
\text { Group }\end{array}$ \\
\hline Non-TGA cases: & & & \\
Unwitnessed attacks & 7 & 7 & 14 \\
Limited or very poor details & 5 & 3 & 8 \\
Other neurological features & 7 & 7 & 14 \\
Post head injury & 1 & 1 & 1 \\
Known active epilepsy & 1 & 18 & 2 \\
Total number excluded & 21 & 51 & 114 \\
TGA cases & 63 & 69 & 153 \\
Total group size & 84 & & \\
\hline
\end{tabular}

and laboratory data revealed no significant or major differences between the 63 prospective and the 51 retrospective definite TGA cases which were therefore combined into a single group of 114 cases. ${ }^{24}$ Similarly the non-TGA cases were combined into a single group of 39 cases.

\section{Clinical Assessment}

All prospective and retrospective patients together with family members (or other informants) had a semi-structured interview. The following information was collected:

1) Demographic data.

2) Details of attack including time of onset, duration, activity at onset, potential precipitating factors within the preceding 24 hours (that is, swimming, sexual intercourse, medical procedures, physical exertion or emotional stress), behaviour during attack and accompanying neurological features. When patients first presented after more than one attack the details of their most recent episode were used in the analysis.

3) Past medical history notably ischaemic or structural heart disease, cerebrovascular disease, diabetes mellitus, peripheral vascular disease, migraine, epilepsy.

4) Smoking history and alcohol consumption. 5) Family history.

All cases had a standard clinical examination, looking particularly for evidence of vascular disease and neurological signs. The following investigations were performed whenever possible: full blood count, liver function tests, fasting lipids and glucose, electrocardiogram (ECG), chest radiograph, electroencephalogram (EEG), CT scan of the brain.

\section{Follow up of patients}

All patients gathered prospectively were reviewed at six months post-attack. Thereafter, follow up was by postal questionnaire to the patients at six-monthly intervals. Similarly, all patients collected retrospectively were kept under six-monthly postal review. Any patient reporting significant medical problems was seen, and their general practitioner was contacted for further medical details. At the end of the study the general practitioners of all the patients were contacted. Information was available in all cases, none has been lost to follow up.

\section{Definitions}

A Transient ischaemic attack (TIA) was defined as an acute loss of focal cerebral or ocular function, with symptoms lasting less than 24 hours and which after adequate investigation was thought to be due to embolic or thrombotic vascular disease. ${ }^{35}$

A Stroke was defined in accordance with the WHO guidelines as a focal neurological deficit (with the exception of cases of subarachnoid haemorrhage) of presumed vascular origin lasting for more than 24 hours or leading to death. ${ }^{36}$ In addition, cases with acute ocular vascular events lasting 24 hours or more were included (that is, retinal infarction, ischaemic optic 
Table 2 Demographic data, basic clinical details and length of follow up of the definite $T G A$ and non-TGA cases

\begin{tabular}{|c|c|c|c|c|}
\hline \multirow[b]{2}{*}{$\begin{array}{l}\text { Age mean }(\mathrm{SD}) \\
\text { Sex ratio } \% \text { men }\end{array}$} & \multicolumn{2}{|c|}{$\begin{array}{l}T G A \text { Cases } \\
n=114\end{array}$} & \multicolumn{2}{|c|}{$\begin{array}{l}\text { Non-TGA Cases } \\
n=39\end{array}$} \\
\hline & $\begin{array}{l}62 \cdot 3 \\
60 \cdot 5\end{array}$ & $(8 \cdot 5)$ & $\begin{array}{l}60 \cdot 8 \\
56 \cdot 4\end{array}$ & $(15 \cdot 0)$ \\
\hline Duration of attacks & & & & \\
\hline $\begin{array}{l}\text { mean }(\mathrm{SD}) \\
\text { median } \\
\text { Presented after single attack }{ }_{0}^{\circ}\end{array}$ & $\begin{array}{r}4 \cdot 2 \\
3 \cdot 5 \\
85 \cdot 1\end{array}$ & $(2 \cdot 8)$ & $\begin{array}{r}7 \cdot 0 \\
3 \cdot 0 \\
66 \cdot 7\end{array}$ & $(12 \cdot 0)$ \\
\hline $\begin{array}{l}\text { Length of follow up } \\
\text { total years } \\
\text { mean months }(\mathrm{SD})\end{array}$ & $\begin{array}{r}326 \cdot 0 \\
34 \cdot 8\end{array}$ & $(27 \cdot 2)$ & $\begin{array}{l}91 \cdot 2 \\
28 \cdot 4\end{array}$ & $(28 \cdot 3)$ \\
\hline
\end{tabular}

neuropathy).

A Myocardial infarction was diagnosed only if confirmed by acute ECG or enzyme changes, or by necropsy.

Deaths were categorised as 1) vascular abdominal or thoracic aneurysm rupture, or sudden death of presumed vascular origin); 2) non-vascular (all others).

A Major vascular event was defined as either a non-fatal stroke, non-fatal myocardial infarct or a vascular death.

\section{Statistical Methods}

Proportions are quoted with $95 \%$ confidence intervals $(95 \% \mathrm{CI})$ described by Gardner and Altman. ${ }^{37}$ The difference between proportions was analysed by odds ratio (OR) with $95 \%$ confidence intervals. If the $95 \%$ confidence intervals included 1.0 the difference between the groups was considered to be non-significant at the $5 \%$ level. ${ }^{38}$ Means are quoted with standard deviations (SD) and the difference between means was analysed by unpaired Student's $t$ tests. Vascular event/mortality rates were adjusted for length of follow up of the group and expressed per 100000 patient years. Outcome was assessed using actuarial (life table) methods based on Kaplan Meier survival curves and statistical analysis was by standard log rank tests of time of the first event, using two-tailed $p$ values. ${ }^{39}$ For analysis of positive and negative predictive values the method described by Sackett and colleagues was used. ${ }^{40}$

\section{Results}

Demographic and basic clinical data are shown in table 2 . There was no significant difference in mean age between the TGA and non-TGA

Figure 1 Age distribution of the TGA and non-TGA cases. (stroke, myocardial infarction, cardiac failure,

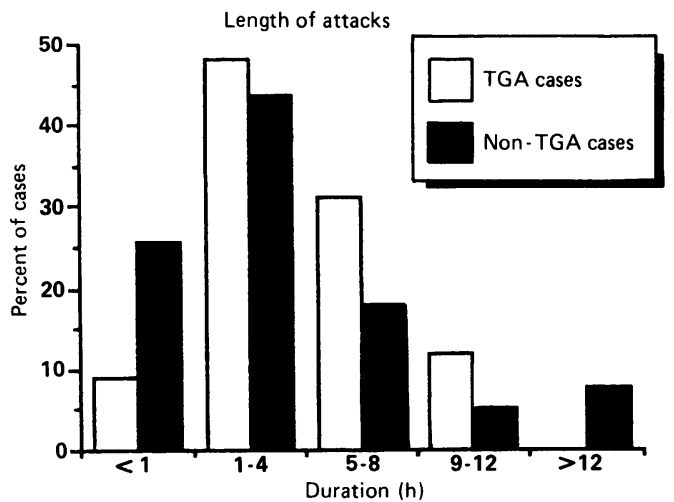

Figure 2 The distrioution of length of attack in the $T G A$ and non-TG $A$ cases.

groups. As shown in figure 1 the ages of the definite TGA patients were normally distributed around the mean with the vast majority being aged between 50 and 80 years; only one was aged less than 40 years. The ages of the non-TGA patients were less normally distributed and the proportion aged below 50 was significantly greater than in the definite TGA group (OR $4 \cdot 2 ; 95 \%$ CI 1.05 to $9 \cdot 2$ ). Social class was characterised according to the Registrar's General classification and a comparison was made with the 1981 census statistics for Oxfordshire ${ }^{41}$. The higher proportion of definite TGA cases in social class I $(17.5 \%$; $95 \%$ CI 10.5 to $24.5 \%$ ) compared with the general population $(7.5 \%$ ) did not reach significance. The distribution of social classes was otherwise extremely similar to that expected from the local census figures.

Number and duration of attacks

The proportion of the non-TGA patients $(67 \%)$ seen after a single attack was significantly less than in the TGA group (85\%) (OR 2.8; $95 \% \mathrm{CI} 1 \cdot 1$ to $7 \cdot 1)$. As shown in fig 2 , the vast majority of attacks in the definite TGA group lasted between one and eight hours: the mean duration was $4 \cdot 2$ (SD $2 \cdot 8$ ) hours and the median duration 3.5 hours. The shortest attack lasted 15 minutes and the longest 12 hours. Episodes lasting less than one hour occurred in only $9 \%$ of the 114 cases. The greater proportion of non-TGA cases with attacks of longer duration was an artefact of the study since patients with episodes of amnesia lasting for greater than 24 hours were, by definition, excluded from the definite TGA group.

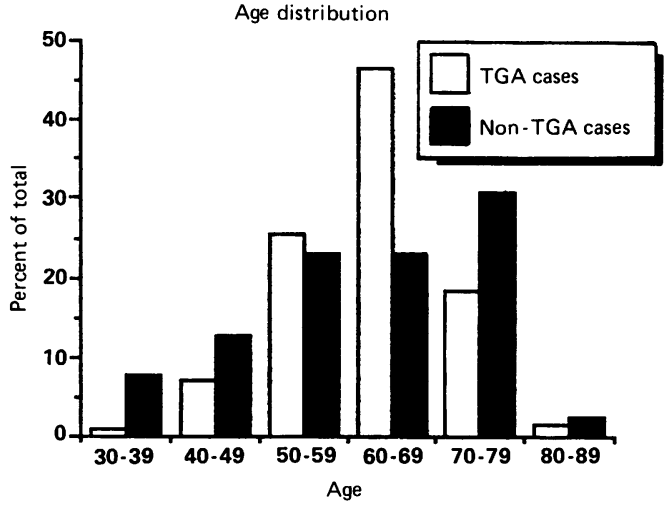

Permanent retrograde amnesia

Patients and witnesses were questioned about the time of onset of the attack to look for any discrepancies that might indicate the presence of a permanent retrograde amnesic gap (that is, permanent loss of memory for events before the apparent onset of the episode). Suitably detailed information was available in 51 of the 63 prospectively ascertained TGA patients. Of these, $40(78 \%)$ had a permanent gap between the last remembered event and the onset of anterograde amnesia. The duration of the gap was usually brief with a median time of one hour (range one quarter to ten hours). In only 
Table 3 Prevalence of behavioural abnormalities and accompanying neurological features during the attack in TGA and non-TGA cases. In the non-TGA group only those witnessed during the attack are included

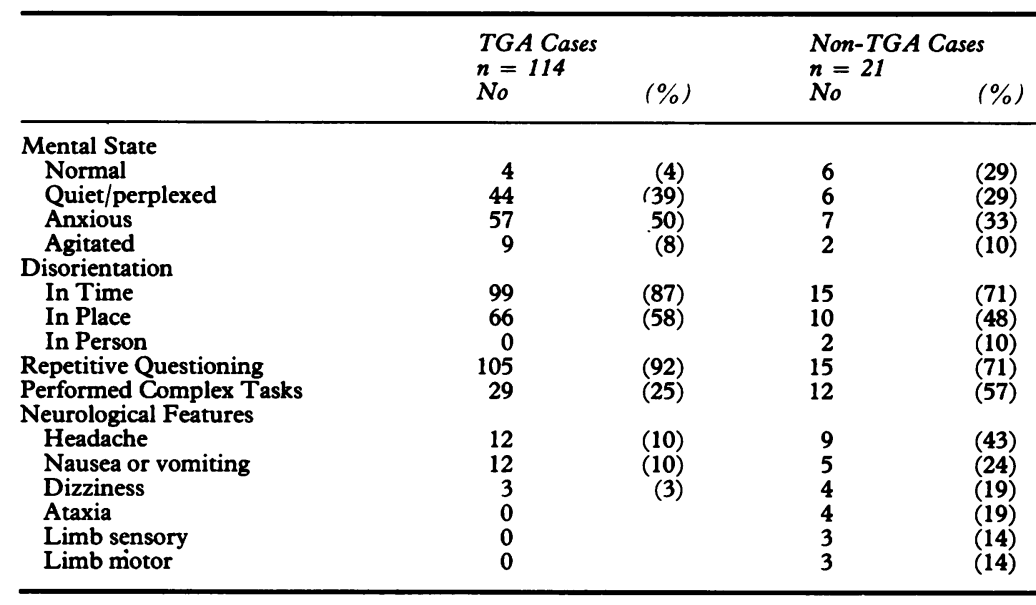

two did it exceed five hours. Since many of the patients in the non-TGA category had unwitnessed or poorly witnessed attacks, suitable information was available in a minority. However, of the 12 cases in whom assessment could be made, six had permanent amnesic gaps of $0.5,4,24,24,98$ and 98 hours, respectively.

\section{Precipitating factors}

Suitably detailed information on putative precipitating events in the preceding 24 hours was available only in the prospectively ascertained TGA cases. In this group of 63 patients two $(3 \%)$ occurred immediately after swimming in cold water, two (3\%) occurred shortly after sexual intercourse, one (2\%) was related to severe pain (from a pilonidal sinus) and three $(5 \%)$ followed immediately after medical procedures (two venepuncture, one acupuncture). Data on physical and emotional stress were clearly less reliable. Nevertheless, nine. $(14 \%)$ reported an emotionally stressful event of at least moderate severity during the 24 hours leading up to the attack. Examples included receiving news that a nephew had cancer, witnessing a severe road traffic accident, involvement in a gas cylinder fire, being told that a close friend had had a heart attack, giving evidence at a medical tribunal, attending the grave of a deceased spouse and a violent family argument. In a further 11

Table 4 Prevalence of abnormal neurological signs detected post-attack in the TGA and non-TG $A$ cases

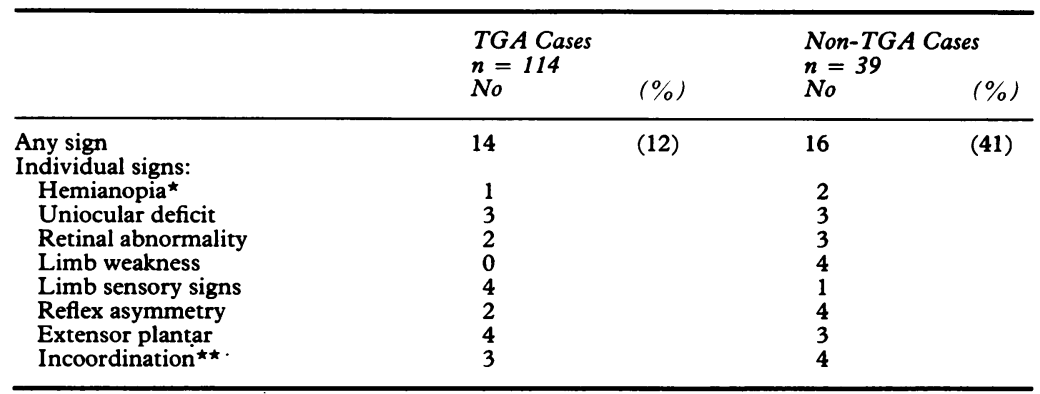

^Hemianopia was due to old strokes and preceded an amnesic episode by months or years.

$\star \star$ Incoordination of gait or limb was mild in all cases. patients $(17 \%)$ the attacks occurred in association with moderate to severe physical exertion. Examples included heavy digging, tree felling, laying concrete garden slabs, digging up a tree and winching a heavy piece of machinery out of a window.

None of the attacks in the 21 prospectively gathered non-TGA patients occurred after swimming, sexual intercourse or medical procedures. However, two $(10 \%)$ occurred after physical exertion, and three $(14 \%)$ were related to emotional stress.

\section{Behaviour during attack}

The TGA and non-TGA groups could not be distinguished on the basis of the behavioural manifestations observed during the attack. Since many of the non-TGA patients had unobserved attacks the analysis was limited to those in whom eye-witness reports were available (see table 3). Disorientation in time was the rule in both groups. Repetitive questioning, which has sometimes been included as part of the defining characteristics of TGA, was present in $92 \%$ of definite cases and $71 \%$ of non-TGA cases. The ability to perform complex manual tasks is often preserved during TGA and was witnessed in $25 \%$ of the cases, in most this consisted of the ability to drive a car. A number of other more unusual activities occurred whilst in an attack; one patient continued making a wooden stool, one was able to continue putting together the alternator of his car, one continued with a bell ringing routine, one managed to put together a bicycle and another continued ballroom dancing (although he could recall only very old dances).

\section{Neurological features}

The presence of clear-cut focal neurological symptoms excluded cases from the definite TGA category. The only commonly noted non-focal symptoms were headache $(10 \%)$, nausea and/or vomiting $(10 \%)$, both of which usually occurred immediately after the attack. In the non-TGA group ataxia, limb weakness or sensory disturbance were the most frequent major symptoms (see table 3 ). The proportion of patients with neurological abnormalities on examination after the attack is shown in table 4. Only a minority $(12 \cdot 2 \% ; 95 \%$ CI $6 \cdot 2$ to $18 \cdot 2 \%)$ of TGA patients had any abnormality, and in these the abnormality was either known to antedate the attack or could be attributed to an unrelated cause. For instance, one patient had signs of an old stroke, one had uniocular visual field loss due to glaucoma, one had a mild myelopathy, and one a diabetic peripheral neuropathy. The prevalence of neurological abnormalities in the definite TGA group was no greater than in an age-matched normal population sample. ${ }^{24}$ However, the prevalence of abnormal neurological signs in the nonTGA group $(41.0 \% ; 95 \%$ CI 25.6 to $56.4 \%$ ) was, as expected (see definition of TGA), significantly greater than in the definite TGA cases (OR 5.0; 95\% CI $2 \cdot 1$ to $11 \cdot 7$ ).

Family history of $T G A$

Two cases of familial TGA were discovered. 
Table 5 Prevalence of vascular risk factors and migraine in the TGA and non-TGA cases

\begin{tabular}{|c|c|c|c|c|c|c|}
\hline & $\begin{array}{l}T G \\
n=\end{array}$ & & & $\begin{array}{l}\text { Non } \\
n=\end{array}$ & $\mathrm{Ca}$ & \\
\hline & $\ddot{N o}$ & $\%$ & $(95 \% C I)$ & No & $\%$ & $(95 \% \mathrm{CI})$ \\
\hline $\begin{array}{l}\text { Ischaemic heart disease: } \\
\text { i) Angina }\end{array}$ & & & & 4 & & $(1-20)$ \\
\hline $\begin{array}{l}\text { 1) Angina } \\
\text { ii) Myocardial Infarction }\end{array}$ & 3 & $\begin{array}{l}0 \\
3\end{array}$ & $\begin{array}{r}(2-10) \\
(0-6)\end{array}$ & 4 & 10 & $\begin{array}{l}(1-20) \\
(1-20)\end{array}$ \\
\hline iii) Either of above & 8 & 7 & $(2-12)$ & 4 & 10 & $(1-20)$ \\
\hline ECG^: Abnormal & 20 & 19 & $(11-27)$ & 10 & 32 & $(16-49)$ \\
\hline Atrial fibrillation* & 3 & 3 & $(0-6)$ & 1 & 3 & $(0-9)$ \\
\hline Hypertension: & & & & & & \\
\hline i) diagnosed at any time & 25 & 22 & $(14-29)$ & 15 & 38 & $(23-54)$ \\
\hline ii) On medication & 20 & 18 & $(11-25)$ & 11 & 28 & $(14-42)$ \\
\hline iii) $\mathrm{BP}>180 / 100$ & 42 & 37 & $(28-46)$ & 18 & 46 & $(30-62)$ \\
\hline Structural heart disease\# & 8 & 7 & $(2-12)$ & 3 & 8 & $(0-16)$ \\
\hline Cerebrovascular disease & 6 & 5 & $(1-9)$ & 4 & 10 & $(1-20)$ \\
\hline Carotid bruit & 10 & 9 & $(4-14)$ & 5 & 13 & $(3-24)$ \\
\hline Diabetes mellitus & 2 & 2 & $(0-4)$ & 2 & 5 & $(0-12)$ \\
\hline Polycythaemia ${ }^{\star}$ & 6 & 5 & $(1-9)$ & 5 & 14 & $(3-25)$ \\
\hline Hypercholesterolaemia $^{\star}$ & 18 & 19 & $(11-27)$ & 6 & 20 & $(6-34)$ \\
\hline Smoking: ever & 56 & 49 & $(40-58)$ & 21 & 54 & $(38-70)$ \\
\hline current & 17 & 15 & $(8-21)$ & 8 & 20 & $(8-33)$ \\
\hline Migraine: Common & 31 & 27 & $(19-35)$ & 11 & 28 & $(14-42)$ \\
\hline Classical & 26 & 23 & $(15-30)$ & 8 & 20 & $(8-33)$ \\
\hline
\end{tabular}

*denotes that not all cases had the relevant investigation.

\#any diastolic murmur, systolic murmur $>2 / 4$ intensity, known cardiomyopathy congenital heart disease or past open heart surgery.

The first, a 60 year old man, presented following a typical attack of TGA lasting eight hours. He reported that his sister and mother had had similar episodes. His sister had been admitted to a local hospital during her attack and examination of the case records confirmed a history characteristic of TGA. His mother's episode had occurred many years before, she had since died and medical records were not available. The second case, a 66 year old woman, presented after a typical episode of TGA. She reported that her brother had had an identical attack some years before, further details were not available. The overall rate of familial TGA in this large series of 114 cases was therefore $1 \cdot 75 \%(95 \%$ CI 0 to $4 \cdot 2 \%)$. There were no familial cases in the non-TGA group.

\section{Vascular risk factors}

The prevalence of risk factors in the two groups is compared in table 5. Although the prevalence of virtually all factors studied was greater in the non-TGA group in no instance did this reach significance. Of the six TGA patients $(5.3 \%)$ with a past history of cerebrovascular events, two had sustained strokes (one vertebro-basilar territory infarct and one cerebral hemisphere infarct) and four TIAs (three carotid and one posterior territory). In contrast, four of the non-TGA patients $(10.2 \%)$ had had a stroke or TIA (one vertebro-basilar TIA, one bilateral occipital haemorrhages, one left hemisphere

Table 6 Comparison of the number of deaths and vascular event in the TGA and non-TGA groups

\begin{tabular}{llllr}
\hline & \multicolumn{2}{c}{$T$ TGA Cases } & \multicolumn{2}{l}{$\begin{array}{l}\text { Non-TGA Cases } \\
n=39 \\
n=114\end{array}$} \\
& No & $(\%)$ & No & $(\%)$ \\
\hline Deaths: Total & 2 & $(1 \cdot 8)$ & 5 & $(12 \cdot 8)$ \\
$\quad$ Vascular & 0 & & 4 & $(10 \cdot 2)$ \\
$\quad$ Non-vascular & 2 & $(1 \cdot 8)$ & 1 & $(2 \cdot 6)$ \\
Stroke (fatal and non-fatal) & 2 & $(1 \cdot 8)$ & 4 & $(10 \cdot 2)$ \\
TIA & 4 & $(3 \cdot 5)$ & 0 & $(7 \cdot 7)$ \\
Myocardial Infarction (fatal and non-fatal) & 0 & & 3 & $(17 \cdot 9)$ \\
Stroke, myocardial infarction or vascular death & 2 & $(1 \cdot 8)$ & 7 & \\
\hline
\end{tabular}

infarct and one amaurosis fugax). This difference was not significant (OR 2.0; $95 \%$ CI 0.3 to $14.9 \%$ ).

\section{Migraine}

Among definite TGA patients a third gave a history of migraine (as diagnosed by a doctor at any time); $27 \%$ had common and $23 \%$ classical migraine (that is, paroxysmal hemicranial headache accompanied by visual or other focal phenomena). The peak age of onset was in the second decade but occasional cases with onset in the sixth or seventh decade were observed. The prevalence of migraine, by all criteria, was not significantly greater in the TGA group than in the non-TGA group.

\section{History of epilepsy}

Patients with active epilepsy were excluded from the definite TGA category. Three $(2 \cdot 6$; $95 \%$ CI 0 to $5.5 \%$ ) TGA patients gave a history of seizures, in all cases many years before their attacks of TGA. In the non-TGA group two $(5 \cdot 1 \% ; 95 \% \mathrm{CI} 0$ to $12 \cdot 0 \%)$ patients had active epilepsy, one as the result of herpes encephalitis many years before and the other as the result of cerebral haemorrhage, both remained on anticonvulsants. Their attacks were indistinguishable from TGA but in view of their known active epilepsy they were included in the non-TGA group.

Alcohol intake and laboratory evidence of covert alcoholism

The majority $(70 \%)$ of TGA patients were in the habit of drinking regular small amounts of alcohol, although in only very few cases was the intake heavy. Using the criteria recommended by the Royal College of Physicians ${ }^{42}$ (more than 20 units per week) $10 \%$ were deemed excessive drinkers. By the less stringent criteria of the Royal College of Psychiatrists ${ }^{43}$ (more than 56 units per week) none of the group were drinking at a dangerous level. Laboratory evidence of covert alcoholism was largely lacking: none of the patients had a raised $M C V$, two had mildly elevated GGTs in the 50-60 iu/1 range which was of doubtful significance, only one patient had a definitely raised GGT of $200 \mathrm{iu} / 1$. The proportion of non-TGA cases who were regular drinkers was not significantly different from the definite TGA group. Laboratory evidence of alcoholism was found in one patient whose GGT was elevated at $100 \mathrm{iu} / 1$. None had a raised $M C V$.

\section{CT brain scans}

All CT scans were performed on a Siemens DR1 with the gantry angled to $10^{\circ}$ above the orbito-meatal line. In the supratentorial compartment contiguous $8 \mathrm{~mm}$ slices were used and below this level the interval was $4 \mathrm{~mm}$. Contrast enhancement was not used routinely. Ninety five $(83 \%)$ of the definite TGA cases, including a consecutive series of 50 prospectively collected patients, were scanned at an average of $\mathbf{4 0}$ days post-attack (range seven to 100 days). There were no instances of cerebral tumour. The only case of major arterial territory infarction was in a patient with a 
Table 7 Comparison of the vascular event incidence and mortality rate (per 100000 patient years of follow up) in the TGA and non-TGA groups

\begin{tabular}{llll}
\hline & $\begin{array}{l}\text { TGA } \\
\text { Cases } \\
n=114\end{array}$ & $\begin{array}{l}\text { Non-TGA } \\
\text { Cases } \\
n=39\end{array}$ & $\begin{array}{l}\text { Ratio } \\
\text { Non-TGA/TGA }\end{array}$ \\
\hline Stroke (fatal and non-fatal) & 613 & 2193 & 3.6 \\
Myocardial Infarction (fatal and non-fatal) & 0 & 3290 & \\
Deaths: Total & 613 & 5384 & 8.8 \\
$\quad$ Vascular & 0 & 4387 & 1.8 \\
$\quad$ Non vascular & 613 & 1097 & 12.5 \\
Stroke, myocardial infarction or vascular death & 613 & 7677 & \\
\hline
\end{tabular}

known old stroke. Eleven (12\%) had small deep white matter/basal ganglia lacunar lesions or peri-ventricular lucencies but in no cases did these involve known memory related structures (medial thalamus and temporal lobe). Cerebral atrophy was present in $15 \%$ and was judged to be mild in $10 \%$ and moderate in $5 \%$.

In the non-TGA group CT scans were performed on $33(85 \%)$ at between 10 and 90 days post-attack. There were no tumours. Two patients with prior strokes had large areas of cerebral infarction. The proportion of cases with small deep white matter lesions or atrophy $(13 \%$ and $15 \%$, respectively) was not significantly different to that in the definite TGA group).

\section{OUTCOME}

1 VASCULAR EVENTS AND DEATHS

The number of deaths and vascular events in the TGA and non-TGA groups are compared in table 6 and the incidence data in table 7 . The two deaths in the TGA group were both due to non-vascular causes (one multiple myeloma, one prostatic carcinoma), whereas of five deaths among non-TGA cases, four were due to vascular causes (two myocardial infarction and two stroke). When standardised for the length of follow up the mortality rate of the non-TGA group was approximately nine times that of the TGA group and Kaplan Meier (lifetable) survival analysis confirmed a significant difference between the groups at the $\mathrm{p}=$ 0.0048 level (fig 3 ). The excess mortality in the non-TGA group was due to an increase in vascular deaths (stroke, myocardial infarction or sudden death). Life-table analysis of survival stratified by cause of death showed a significant difference between the groups for vascular deaths $(p=0.006)$ but not for nonvascular deaths $(p=0.47)$.

When fatal and non-fatal vascular events (stroke, myocardial infarction or sudden death) were combined the difference between the

Figure 3 Kaplan Meier survival curves (till death) comparing the $T G A$ and non-TGA cases.

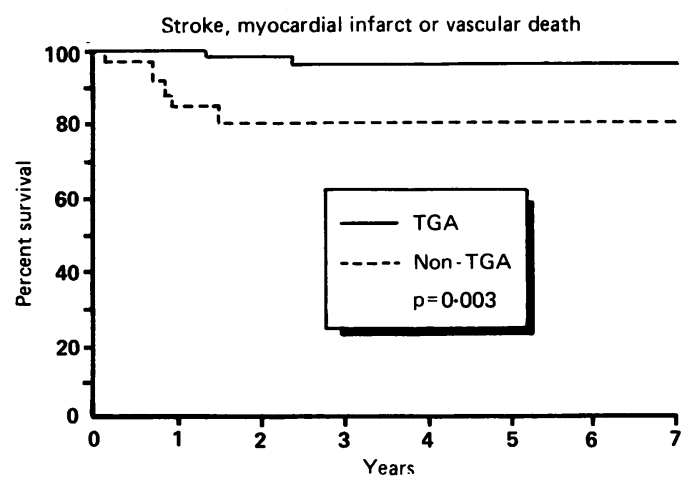

Figure 4 Kaplan Meier survival curves for survival free from stroke, myocardial infarction or sudden death (excluding non-vascular deaths) comparing the TGA and non-TG $A$ cases.

groups was highly significant $(\mathrm{p}=0.003$, see fig 4). Expressed as an annual rate, TGA patients had a $0.6 \%$ per annum rate of major vascular events compared with $7.7 \%$ in nonTGA patients.

\section{EPILEPSY}

Of the total 153 patients in the study, 14 became overtly epileptic during follow up. Eight of these were in the definite TGA category and six in the non-TGA group. The proportion of cases in the TGA group who developed epilepsy although smaller $(7.0 \%$, $95 \%$ CI 2.3 to $11 \cdot 7 \%$ ) was not significantly different (OR $2.4 ; 95 \%$ CI 0.6 to 9.6 ) to the proportion of non-TGA cases $(15.4 \% ; 95 \% \mathrm{CI}$ $4 \cdot 1$ to $26 \cdot 7 \%$ ). None of these patients had a history of epilepsy before their first attack of amnesia. Most developed epilepsy of complex partial type.

Of the eight TGA patients with a subsequent diagnosis of epilepsy, seven developed episodes of altered consciousness with blankness, staring or automatism followed by periods of amnesia, often with repetitive questioning. The other patient developed major tonic-clonic generalised seizures. The time to onset of epilepsy was less than one year from the most recent presenting attack of TGA in all but two cases. The range was from four weeks to three years. The annual rate of epilepsy development was $2.5 \%$, but as virtually all patients manifesting epilepsy did so within 12 months the rate for the first year of follow up was approximately $7 \%$. CT brain scans and routine EEG recordings performed after the presenting TGA episode were normal in all cases.

Of the six non-TGA patients who developed epilepsy five had been included in this category because their original attack(s) had been poorly witnessed. The other patient, included because of additional features during the presenting amnesic episode, appeared vague, complained of hemisensory symptoms, was weepy and could not recall his wife's name. Six months later he had a further similar episode but on this occasion was clearly more confused and intermittently vacant. An EEG during this attack showed paroxysmal bilateral temporal sharp waves. All six developed complex partial seizures, four within six months of their original presentation. CT scans were normal in all cases. EEGs performed after their present- 
ing attacks were abnormal in five, but only two showed clear-cut epileptic activity (runs of bitemporal spikes or sharp waves), the others had non-specific focal slow waves. It was noted that of the 22 patients included in the nonTGA category because of poorly described or unwitnessed attacks (without other neurological features), five $(23 \%)$ have subsequently developed seizures.

Clinical features predictive of subsequent epilepsy There was a striking association between the number of attacks at presentation and the subsequent manifestation of epilepsy in both the definite TGA and non-TGA cases. Of the 17 TGA cases initially presenting after more than one attack six subsequently developed epilepsy $(35.3 \% ; 95 \%$ CI 12.6 to $58.0 \%$ ), whereas of the 97 assessed after a single attack only two became epileptic $(2 \cdot 1 \% ; 95 \% \mathrm{CI} 0$ to $5.0 \%$ ). This difference was highly significant (OR $25.9 \%$; 95\% CI 6.1 to 109). The same trend was apparent in non-TGA cases. Of the 13 patients presenting after multiple attacks, six became epileptic $(46 \cdot 2 \% ; 95 \%$ CI $19 \cdot 1$ to $73.3 \%$ ). By contrast, none of the 26 patients assessed after a single episode developed epilepsy. This difference was also highly significant (OR $43 \cdot 7 ; 95 \%$ CI $3 \cdot 8$ to 500 ).

The duration of presenting episode was the other predictive feature. Of 10 definite TGA patients with attacks lasting less than one hour five developed epilepsy $(50 \% ; 95 \%$ CI 19 to $81 \%$ ), whereas of 104 patients with attacks of one hour or more only three developed seizures $(2.9 \% ; 95 \%$ CI 0 to $6 \%)$. This difference was highly significant (OR $33.7 ; 95 \%$ CI 8.3 to 136). Other clinical features not predictive of subsequent epilepsy included age, sex, behaviour during the attack and activity at onset.

Analyses of the positive and negative predictive values for epilepsy development after TGA revealed the following results. Of the eight patients who subsequently developed epilepsy four had both multiple and brief attacks (that is, less than one hour). Whereas of the 106 who did not develop epilepsy none had both features. The positive predictive value for epilepsy when both features were present was thus $100 \%$ and the negative predictive value $96.4 \%$. Similar calculations showed that the positive predictive value when one or both features was present was $33 \cdot 3 \%$. Duration of attack was a better predictor than multiplicity since the positive predictive value of brief attacks was $50.0 \%$ and that of multiple attacks $35.3 \%$. The negative predictive values in both cases was very high at $97 \cdot 1 \%$ and $97.9 \%$, respectively. Thus, the likelihood of developing epilepsy when both factors are absent is extremely low. Whereas, the likelihood is extremely high when both are present. When either factor alone is present the likelihood is between a third and a half.

\section{RECURRENT AMNESIA}

The recurrence rate (excluding cases with subsequent epilepsy) was low in both the TGA. and non-TGA groups: nine of 114 TGA patients $(7.9 \% ; 95 \%$ CI 2.9 to $12.8 \%$ ) and four of the 39 non-TGA cases $(10.3 \% ; 95 \%$ CI 0.8 to $19.8 \%$ ) had a further attack of amnesia. This difference did not reach significance. Expressed as an annual rate approximately $3 \%$ of TGA patients experienced a recurrence each year.

\section{Discussion}

The results of this study show that the proposed criteria for TGA can be applied to the majority of patients presenting with acute transient memory loss, and with the exception of a small and largely predictable subgroup who subsequently develop epilepsy, they designate a group with a good prognosis. By contrast, patients with attacks which do not fulfil the criteria for TGA have a significantly worse outcome. This suggests that there are several distinct causes of transient amnesia. There is little support for a cerebrovascular aetiology for pure TGA (as defined) but it may be responsible for the small proportion of cases in whom added neurological features are present during the attack. The question of the aetiology of pure TGA is considered in the context of the complementary case-control study. ${ }^{24}$

The demographic features of the TGA patients in our study were very similar to those previously reported. The vast majority of attacks occurred between the ages of 50 and 80 . The mean age in twelve large series was 61 years. ${ }^{26-1216262744}$ TGA appears to be more common in men although the reported sex ratio has varied considerably; in the larger series (cited above) males predominated in seven and females in five. The slight bias in favour of social class I may have reflected a difference in referral pattern. It seems very likely that patients from higher social groups would be preferentially referred by their general practitioners. Since the diagnosis depends upon accurate eye witness reports, less articulate families from lower social classes may have difficulty in describing the complex symptomatology of TGA to their general practitioners, and are perhaps less likely to request a specialist opinion.

Occasional authors have reported multiple attacks at presentation of TGA in up to $50 \%$ of their cases $^{6}$ but most series have included between 10 to $30 \%$ of cases with more than one episode. ${ }^{12162526}$ In our series $85 \%$ presented after a single attack. The mean duration of attacks in the present study was relatively brief at 4.2 hours and attacks of greater than 12 hours were exceptional. In two recent large studies the mean duration was in the order of six hours. ${ }^{2627}$

Most patients have a permanent retrograde amnesic gap for events before the clinical onset of TGA. The only author to have previously drawn attention to this phenomenon is Fisher. ${ }^{15}$ In his review of 76 personal cases, almost a half had a permanent retrograde gap, and the distribution of duration of retrograde amnesia was very similar to that observed in our cases. The number of patients in the non- 
TGA group in whom assessment could be made was too small to draw any firm conclusions. However, it was notable that exceptionally long permanent retrograde deficits were present in several non-TGA patients.

Despite the fact that in only a minority of patients could TGA be linked to an identifiable precipitating factor, the proportion associated with some activities such as swimming or medical procedures appeared to be higher than would be expected in a control population of this age. There have been no previous prospective studies of the frequency of precipitating factors. In the large retrospective study by Miller et $a l,{ }^{27} 7 \%$ of their 347 attacks were preceded by sexual intercourse, temperature extremes or medical procedures and $22 \%$ were associated with emotional stress or exertion. In a study based on case note review, Shuping et $a l^{9}$ found that in $15 \%$ of their 41 cases the attacks were associated with bathing in cold water, sexual intercourse or strenuous activity. It is possible that the apparently high prevalence of unusual precipitating factors results from referral bias, in that patients with attacks occurring after such events may be more likely to be referred to hospital. The role of physical and emotional stress in the aetiology of TGA remains unsettled. A controlled study comparing life and other events in TGA patients and normal subjects would be very helpful, but clearly very difficult to conduct properly.

It is well established that alcoholics suffer from periods of amnesia, so-called "alcoholic blackouts". ${ }^{33}$ There was no suggestion, however, that alcohol played an aetiological role in the vast majority of TGA cases in this study. Most patients took only a small quantity of alcohol. None were known to be alcoholics and although $10 \%$ of the TGA group did exceed the stringent Royal College of Physicians ${ }^{42}$ recommended upper level, none drank above the Royal College of Psychiatrists $^{43}$ level for addiction, and laboratory evidence of covert alcoholism was absent.

The first report of familial TGA was that by Corston and Godwin Austen. ${ }^{30}$ Since then a number of other authors have reported further cases. $^{3132}$ There have been no previous attempts to estimate the frequency of a positive family history in a large series. Our study suggests a prevalence in the order of $2 \%$. Since TGA is a relatively unusual condition, with an estimated minimum annual incidence of approximately two per $100,000,{ }^{24}$ the finding of a familial rate of $2 \%$ represents a very substantial (hundred fold) increase above the expected familial rate.

The patients with definite TGA had a very good prognosis. Their rate of subsequent major vascular events was less than $1 \%$ per annum, which was probably not above that expected for a similarly aged normal population. This finding is in keeping with the two large follow up studies of TGA patients reported from the Mayo Clinic ${ }^{27}$ and from Denmark ${ }^{26}$ in which virtually identical diagnostic criteria were used. In both of these studies the rate of subsequent stroke was no higher than that expected in the local community. Furthermore, the results of our complementary case-control study ${ }^{24}$ showed that the incidence of both vascular events and deaths was very significantly greater following TIA than following TGA. The earlier follow up studies, which found much higher rates of subsequent vascular events and deaths, had small patient groups and used broader selection criteria including a substantial proportion of patients with additional neurological features during the attack. ${ }^{7-11}$

One unexpected finding was the high rate of subsequent epilepsy in the TGA patients even when strict diagnostic criteria were applied. Presumably their presenting attacks were seizures in which the brief epileptic features went unnoticed and in whom amnesia was the most predominant feature. Two important clinical features predicted a high likelihood of epilepsy development: multiple attacks at presentation and brief episodes lasting less than one hour. The positive predictive value of epilepsy development when both features were present was $100 \%$, when only one feature was present the positive predictive value fell to between a half and a third. However, the likelihood of epilepsy development in the absence of these features was no greater than $4 \%$. Clearly, patients with either of these features should be followed closely and given a more guarded prognosis. Unlike patients without either predictive feature, such patients should perhaps be advised against driving, at least for 12 months post-attack. CT scans were normal in all subsequently "epileptic" patients and the routine EEG performed post-TGA attack was not helpful. It should be noted that other clinical features, such as repetitive questioning and retrograde amnesia did not separate TGA patients who developed epilepsy from those with a good outcome. Clearly not all cases of TGA are due to epilepsy, but the same indistinguishable clinical phenomenon of transient anterograde and retrograde amnesia may arise following complex partial seizures.

Previous follow up studies of TGA patients have not revealed such a high rate of epilepsy. ${ }^{15-1244}$ This is surprising because most authors have used much broader diagnostic criteria and have included patients with unwitnessed episodes of amnesia or with additional neurological features during the episode. Since case ascertainment in previous studies was entirely retrospective it is conceivable that patients who later developed epilepsy were excluded because it was decided that their original attack could not have been true TGA.

The recurrence rate of pure TGA was low. In this study only $8 \%$ had a further attack. When adjusted for length of follow up the rate was approximately $3 \%$ per annum. The latter figure is very close to that reported by Hinge et $a l^{26}$ who found an annual recurrence rate of $4.7 \%$ in their series of 74 cases. Other authors have reported rates between $6 \%$ and $57 \%$ but have not adjusted for length of follow up. ${ }^{78111244}$

Previous studies of CT scan abnormalities following TGA have produced apparently conflicting results. A number of authors have 
reported case series with a high prevalence of abnormalities, notably areas of presumed infarction. ${ }^{11} 122829$ However, these series have all included patients with major neurological deficits (hemianopia; hemiparesis) during the attack and/or permanent memory loss; such cases would now be more properly classified as amnestic strokes. ${ }^{45}{ }^{46} \mathrm{It}$ is therefore not surprising that a number of cases with infarction in the left posterior cerebral artery territory were found. By contrast, Crowell et al ${ }^{16}$ found no significant abnormalities in 12 patients having CT scans. Caplan ${ }^{25}$ after reviewing the CT abnormalities in all reported cases stated that insufficient data were available to reach any general conclusions and that there was a need for a study of CT scan abnormalities in a larger group of patients with clearly defined TGA. The results of this study confirm the normality of CT scans in patients with clearly defined TGA. On the basis of this evidence, we would not recommend routine scanning of patients presenting after a single attack of definite TGA of more than one hour in duration and in whom no relevant abnormalities are detected on neurological examination. In patients with atypically brief, or recurrent attacks or who do not fulfil the criteria for TGA, routine CT scanning should perhaps be performed.

The clinical features, excluding those used as part of the diagnostic criteria, which separated the definite TGA and non-TGA patients were relatively few. A significantly greater proportion presented after more than one attack and were aged less than 50 years. Exceptionally long permanent retrograde memory deficits were present in several non-TGA patients and neurological abnormalities post-attack were significantly more common. However, the latter was to be expected since a third of the non-TGA cases were included in this category specifically because of the presence of additional neurological features during the attack. Although the prevalence of vascular risk factors was consistently greater in the nonTGA group this difference did not reach statistical significance, perhaps because of the much smaller number of cases in this category. A larger epidemiological study comparing "pure TGA" with non-TGA cases is required to settle this question.

The natural history of non-TGA patients was, however, significantly different to that of the pure syndrome. The incidence of major vascular events was more than 10 times greater than in the "pure TGA" group. Patients with unobserved episodes of amnesia had a particularly high rate of subsequent epilepsy. The implication of these findings is clear. Patients presenting with an amnesic episode which is either unwitnessed, poorly documented or accompanied by focal neurological features should be closely observed and given a guarded prognosis. These findings also suggest that the non-TGA group are indeed a separate population. A third of the cases in this category had focal neurological features during the attack. It seems likely that these cases, who represent only a minority of the total cases with transient amnesia, do have a thrombo-embolic cerebrovascular aetiology, in contrast to the "pure TGA" cases.

In conclusion, transient amnesia is a heterogeneous clinical syndrome. The proposed criteria for TGA do indeed define a population with a good outcome and little to suggest cerebrovascular disease as a cause of their amnesia. In this group, which we would designate "pure TGA", there is no need for extensive investigation. Such patients can be confidently assured of a good prognosis and can be advised to continue driving. A subset of "pure TGA" patients, largely identifiable because of atypically brief or recurrent attacks, develop epilepsy. Patients presenting with brief or recurrent attacks are best designated as "probable epileptic amnesia" cases. A more guarded prognosis and more complete investigation are indicated in these patients. A further small group of patients whose episodes do not fulfil the criteria for TGA because of the occurrence of additional focal neurological features during the attack have a significantly worse prognosis for serious vascular events. It seems that in these cases, who represent only a minority of cases presenting with transient amnesia, cerebrovascular disease is probably the responsible aetiological agent, such cases should thus be classified as "probable transient ischaemic amnesia".

This study was supported by a grant from the Medical Research This study was supported by a grant from the Medical Research computer programming.

1 Fisher CM, Adams RD. Transient global amnesia. Tran Amer Neurol Assoc 1958;83:143-6.

2 Fisher CM, Adams RD. Transient global amnesia. Acta Neurol Scand 1964;40 (suppl 9):1-83.

3 Bender MB. Single episode of confusion with amnesia. Bull N Y Acad Med 1960;36:197-207.

4 Evans JH. Transient loss of memory, an organic mental syndrome. Brain 1966;89:539-48.

5 Godlewski S. Les episodes amnesiques (transient global amnesia). Etude clinique basee sur 33 observation amnesia). Etude clinique basee sur 33

6 Heathfield KWG, Croft PB, Swash M. The syndrome of transient global amnesia. Brain 1973;96:729-36.

7 Mathew NT, Meyer JS. Pathogenesis and natural history of transient global amnesia. Stroke 1975;5:303-11

8 Fogelholm R, Kivalo E, Bergstrom. The transient global amnesia syndrome; an analysis of 35 cases. Europ Neurol 1975;13:72-84.

9 Shuping JR, Rollinson R, Toole JF. Transient global amnesia. Ann Neurol 1980; 7:281-5.

10 Jensen TS, Olivarius B de F. Transient global amnesia-its clinical and pathophysiological basis and prognosis. Acta Neurol Scand 1981;63:220-30.

11 Cattaino G, Querin F, Pomes A, Piazza P. Transient global amnesia. Acta Neurol Scand 1984;70:385-90.

12 Kushner MJ, Hauser WA. Transient global amnesia: a casecontrol study. Ann Neurol 1985;18:684-91.

13 Gilbert GJ. Transient Global Amnesia: Manifestation of medial temporal lobe epilepsy. Clin Electroencephalography 1978;9:147-52.

14 Rowan AJ, Protass LM. Transient global amnesia: clinical and electroencephalographic findings in 10 cases. Neurology 1979;29:869-72.

15 Fisher CM. Transient global amnesia. Precipitating activities and other observations. Arch Neurol 1982; 39:605-8.

16 Crowell GF, Stump DA, Biller J, McHenry LC, Toole JF. The transient global amnesia-migraine connection. Arch Neurol 1984;41:75-9.

17 Caplan LR, Chedru F, Lhermitte F, Mayman C. Transient global amnesia and migraine. Neurology 1981;31:1167-70. Wales LR, Nov AA. Transient global amnesia: complication of cerebral angiography. $A J N R$ 1981;2:275-77.

19 Pexman JHW, Coates RK. Amnesia after femorocerebral Pexman JHW, Coates RK. Amnesia after
angiography. $A J N R$ 1983;4:979-83.

20 Aimard G, Trillet M, Perroudon C, Tommasi M, Carrier H. Ictus amnesique symptomatique d'un glioblastome interessant de le trigone. Rev Neurol 1971;124:392-5.

21 Lisak RP, Zimmerman RA. Transient global amnesia due to a dominant hemisphere tumour. Arch Neurol 1977;34: 317-8. 
22 Landi G, Giusti MC, Guidotti M. Transient global amnesia due to left temporal haemorrhage. $J$ Neurol Neurosur Psychiatry 1982;45:1062-3.

23 Hodges JR. Ward CD. Observations during transient global amnesia. A behavioural and neuropsychological study of five cases. Brain 1989;112:595-620.

24 Hodges JR, Warlow CP. The aetiology of transient global amnesia: A cases-control study of 114 cases with prospective follow-up. Brain 1990;113:639-57.

25 Caplan LR. Transient global amnesia. In: Vinken PJ, Bruyn $\mathrm{GW}$, Klawans HL, eds. Handbook of clinical neurology, Vol 1 (45). Amsterdam: Elsevier Science Publishers, 1985:205-18.

26 Hinge $\mathrm{HH}$, Jensen TS, Kjaer M, Marquardsen J, Olivarius $B$ de $F$. The prognosis of transient global amnesia: results of a multicenter study. Arch Neurol 1986;43:673-6.

27 Miller JW, Petersen RC, Metter EJ, Millikan CH, Yanagihara $T$. Transient global amnesia: clinical characteristics and prognosis. Neurology 1987;37:733-37.

28 Ladurner G, Skvarc A, Sager WD. Computer tomography in transient global amnesia. Eur Neurol 1982;21:34-40.

29 Matias-Guiu J, Colomer R, Segura A, Codina A. Cranial CT Scan in transient global amnesia. Acta Neurol Scand 1986;73:298-301.

30 Corston RN, Godwin-Austen RB. Transient global amnesia in four brothers. J Neurol Neurosurg Psychiatry 1982; in four br:

31 Stracciari A, Rebucci GG. Transient global amnesia and migraine-familial incidence. J Neurol Neurosurg Psychiatry 1986;49:716-9.

32 Dupuis MJM, Pierre PH, Gonsette RE. Transient global amnesia and migraine in twin sisters. $J$ Neurol Neurosurg Psychiatry 1987;50:816-24.

33 Godwin DC, Bruce Crane J, Guze SBB. Phenomenological aspects of alcoholic blackouts. $B r J$ Psychiatry 1969;115:1033-8.

34 Bamford J, Sandercock P, Dennis M, et al. A prospective study of acute cerebrovascular disease in the community: the Oxfordshire Community Stroke Project 1981-1986 I. Methodology, demography, and incident cases of first eve stroke. J Neurol Neurosurg Psychiatry 1988;51:1378-80.

35 Warlow CP, Morris PJ. Transient ischaemic attacks. New York: Marcel Decker, 1982:ix.

36 Hatano S. Experience from a multicentre stroke register: a preliminary report. Bull WHO 1976;54:541-53.

37 Gardner MJ Altman DG Confidence intervals rather than p values: estimation rather than hypothesis testing. $\mathrm{Br}$ Med J 1986;292:746-50.

38 Morris JA Gardner MJ. Calculating confidence intervals for relative risk (Odds ratios) and standardised ratios and relative risk (Odds ratios) and

39 Peto R, Pike MC, Armitage P, et al. Design and analysis of randomized clinical trials requiring prolonged observations of each patient. II Analysis and examples. $\mathrm{Br} J$ Cancer 1977;35:1-35.

40 Sackett DL, Haynes RB, Tugwell P. Clinical epidemiology: A basic science for clinical medicine. Boston: Little, Brown and Company, 1985:59-138.

41 Office of Population Censuses and Surveys (OPCS). Census 1981. Key statistics for urban areas. London: HMSO, 1984

42 Royal College of Physicians. The medical consequences of alcohol abuse: $A$ great and growing evil. London: Tavistock, 1987 .

43 Royal College of Psychiatrists. Alcohol and alcoholism: Report of a special committee. London: Tavistock, 1979.

44 Nausieda PA, Sherman IC. Long-term prognosis in transausieda PA, Sherman IC. Long-term prognosis
sient global amnesia. JAMA 1979;241:392-3.

45 Guberman A, Stuss D. The syndrome of bilateral paramedian thalamic infarction. Neurology 1983;33: 540-6.

46 DeRenzi E, Zambolin A, Crisi G. The pattern of neuropsychological impairment associated with left posterior cerebral artery infarcts. Brain 1987;110:1099-116. 